\title{
Arrhythmia Artifact
}

National Cancer Institute

\section{Source}

National Cancer Institute. Arrhythmia Artifact. NCI Thesaurus. Code C87035.

An imaging artifact resulting from a patient arrhythmia. 